\title{
An investigation of hygrothermal aging effects on High Strain Rate Behaviour of Adhesively Bonded Composite Joints
}

\author{
M. Nachtane ${ }^{1,2}$, M. Tarfaoui ${ }^{1}$, S. Sassi ${ }^{1}$, A. El Moumen ${ }^{1}$, D. Saifaoui ${ }^{2}$ \\ ${ }^{1}$ ENSTA Bretagne, IRDL - UMR CNRS 6027, F-29200 Brest, France \\ ${ }^{2}$ FSAC - UH2C, Laboratory for Renewable Energy and Dynamic Systems, Morocco
}

\begin{abstract}
:
Composite materials have vast range of engineering applications because of their outstanding mechanical performance, low density and cost effectiveness. Marine industry and naval structures are one of the applications where composites are gaining importance rapidly however, there are confronted with extreme environmental conditions in addition mechanical behaviour. Therefore, it is important to comprehend the behaviour of these materials not only under mechanical loads but also under environmental effects. For that reason, the objective of this paper is to study the effects of hygrothermal aging phenomenon on the behaviour of adhesively bonded composite joints at high strain rates. Dynamic compressive properties and microstructural damage progression is analysed utilizing the Split Hopkinson Pressure Bars (SHPB) technique. The stress-strain behaviour of composite specimens subjected to severe hygrothermal conditions have been studied at high strain rates ranging from 445 to $1240 \mathrm{~s}^{-1}$. In addition, Keyence and scanning electron microscopic (SEM) is used to study the significant damage modes. The results indicated change in dynamic properties and damage behaviour because of the environmental effects.
\end{abstract}

Keywords: Hygrothermal aging, Mechanical behaviour, Adhesive joints, Dynamic compression, In-plane tests, SHPB technique.

\section{Introduction}

Composite materials are being used progressively in a wide range of industries and applications due to their diverse advantages over traditional materials. They are used in marine, aerospace, and other industries, however, one of the most essential condition for a structural composite is its capacity to retain its loadbearing ability for longer period of time under critical environmental conditions (temperature variations, moisture, oxidation, microbiological attack...) [1, 2]. In the past decades, the reinforcement and reparation of marine engineering structures utilizing GFRP laminates had attracted a large deal of attention [3]. In addition, adhesively bonded joints had been considered as premium choice for joining composite structures for many years because of their high fatigue resistance; good vibration damping properties; elimination of galvanic corrosion phenomenon and the uniform distribution of mechanical stress over the joint [4]. Therefore, it has become requisite to comprehend the dynamic behaviour of adhesively bonded composite joints under critical loads for developing constitutive models [5].

Numerous composite structures and assemblies had been applied and preferred over conventional materials such as metal, ceramic in applications which were subjected to extreme outdoor environment. Therefore, the importance of studying the effect of environmental conditions such as hygrothermal aging on mechanical properties of adhesively bonded assemblies under dynamic impact has become increasingly evident during recent 
years [6]. Many researchers studied the effect of seawater on polymer composites and how it led to the degradation of their performance [7]. For example, environmental exposure could result in reduction of interfacial stress transmissibility because of matrix plasticization, chemical changes and mechanical degradation. Matrix plasticization could reduce matrix modulus while chemical degradation could cause hydrolysis of bond. Mechanical degradation could be because of the strain caused by the matrix and in addition, an interfacial reaction could induce various morphological modifications in interface between the fibre and the matrix $[8,9]$. However, very little information was found in the literature on the study of damage mechanisms that could show diverse behaviour even in the absence of the effect of important environmental factor such as seawater on degradation of fatigue resistance. So, it was significant to better comprehend the mechanisms and extent of seawater degradation.

Various studies had reported the hygrothermal degradation of reinforced epoxy composites [10,11, 12, 13 and 14]. Schutte showed that the hygrothermal degradation of glass fibre composites included the degradation of the fibre reinforcement, polymer resin matrix, and fibre/matrix interface. However, various investigations showed that vinylester reinforced composites presented better performance in comparison with epoxy based composites because of their high durability, low cost, and resistance to thermal aging [15]. Therefore, vinylester based resins are usually chosen as the matrix material for composite structures [16, 17]. Jiang et al. [18] used the experimental and numerical investigation to study the influence of moisture absorption and hygrothermal aging on glass-fibre-reinforced polymer laminates and structural adhesive. The results showed that the square and rectangular samples lost their mass below $40^{\circ} \mathrm{C}$ conditions. Pillay and his colleagues [19] evaluated the effects of moisture and UV exposure on the interlaminar shear strength, flexural strength, and low-velocity impact resistance of the composite materials. Similarly, Hosur et al. [20] performed an experimental investigation on unidirectional graphite/epoxy samples under dynamic compression loading conditions at room and elevated temperatures of $51.7^{\circ} \mathrm{C}$, $121.1^{\circ} \mathrm{C}$, and $190.6^{\circ} \mathrm{C}$. The influence of temperature and fabric architecture on the dynamic properties and failure mechanisms was reported in detail.

Recently, Sousa et al. [21] examined the influence of thermal cycles on adhesively bonded assemblies used in civil engineering applications. Benyahia et al. [22] studied the mechanical properties of composite pipes under different temperatures ranging from -40 to $80{ }^{\circ} \mathrm{C}$. Experimental results showed an increase in the mechanical degradation of polymer pipes with an increase in the temperature. Jojibabu et al. [23] studied the effect of adding carbon nano-fillers on the degradation of epoxy adhesive joints subjected to hygrothermal aging. The authors concluded that the addition of nano-fillers in the adhesive joints showed higher joint strength as compared to neat epoxy joints after aging process. Akderya et al. [24] investigated the effects of thermal aging on tensile properties of adhesively bonded single lap joint of fibre/epoxy composites at three different temperatures $\left(18^{\circ} \mathrm{C}, 25^{\circ} \mathrm{C}\right.$ and $\left.70^{\circ} \mathrm{C}\right)$. It was observed from the results that thermal aging at $-18{ }^{\circ} \mathrm{C}$ increased the load carrying ability of the joint while impacts applied to the joints reduced it. Moreover, decrease in tensile fracture strength of the joint was observed at the temperatures $-18^{\circ} \mathrm{C}$ and $70^{\circ} \mathrm{C}$. Afterward, Rafiq [25] studied the effect of nano clay on the flexural properties and water absorption resistance of glass fiber-reinforced epoxy composites at different temperatures. The results showed that the maximum water absorption was decreasing by increasing the amount of nano clay loading and it was also observed that the moisture dispersion was about $80 \%$ higher at $80^{\circ} \mathrm{C}$ than that at room temperature. After the absorption process, flexural test were conducted on all the specimens and results showed that specimen with $1.5 \mathrm{wt}$. \% loading of nano clay showed similar behaviour as of the unexposed specimen thus, showing optimal flexural performance 
under exposed environment. Exposure to moisture resulted in $36 \%$ and $8 \%$ reduction in flexural strength the nano composite at $80^{\circ} \mathrm{C}$ and room temperature respectively.

So, a significant amount of research had been performed previously to understand the influence of hygrothermal effect on the mechanical behaviour of polymer composites at very low strain rates. But, little or no information regarding the experimental study of the hygrothermal effect on the dynamic response of the composites and adhesively bonded composites at high strain rates could be found. On this context, the present experimental study was carried out to study the influence of hygrothermal effect on the mechanical behaviour of the adhesive bonded composite joints at high strain rates using the Split Hopkinson Pressure Bar (SHPB) machine. At first, adhesively bonded composite samples were subjected to hygrothermal aging conditions $\left(50^{\circ} \mathrm{C}-80 \% \mathrm{RH}\right.$ (relative humidity)) and then in-plane dynamic compression tests were conducted at different impact pressure from 1 to 4 bar using SHPB technique. The results showed that the moisture absorption led to the degradation of dynamic compressive failure strength at high strain rates. Damage mechanisms such as micro buckling kinking and splitting of the fibres were the major failure modes observed in the specimens when subjected to in-plan dynamic compression.

\section{Experimental procedure}

\subsection{Materials and Specimen Geometry}

The material examined in this study was fabricated by using polyester polymer and 45 biaxial fibre-glass mat with $0.286 \mathrm{~mm}$ in thickness. The polyester polymer was studied in this investigation because it could be used in marine environment as an alternative to the other polymers such as epoxy resin because of its cost effectiveness and good characteristics in a corrosive medium and under high temperatures. A NORPOL polyvinylester adhesive was used to develop an adhesive bond of $1 \mathrm{~mm}$ in thickness between the two composite parts. The physical and mechanical properties of the materials used are listed in Tables 1, 2 and 3 [26].

Table 1: Physical properties of the fiber glass mat

\begin{tabular}{lccc}
\hline Sequence & $\begin{array}{c}\text { Weight } \\
\left(\mathbf{g} / \mathbf{m}^{\mathbf{2}}\right)\end{array}$ & Material & $\begin{array}{c}\text { Linear density } \\
(\mathbf{t e x})\end{array}$ \\
\hline$+45^{\circ}$ & $451( \pm \mathbf{5})$ & E-Glass & 600 \\
$-45^{\circ}$ & $451( \pm \mathbf{5})$ & E-Glass & 600 \\
Stitching & $12( \pm \mathbf{5})$ & PES 76 dtex & \\
Total area weight & $912( \pm \mathbf{5})$ & Binder & Warp \\
\hline
\end{tabular}

Table 2: Mechanical properties of orthotropic layer (glass/vinylester)

\begin{tabular}{ll}
\hline Properties & Values \\
\hline Density $\left(\mathrm{kg} / \mathrm{m}^{3}\right)$ & 1960 \\
Young's modulus $(\mathrm{MPa})$ & $E_{1}=48110, E_{2}=E_{3}=11210$ \\
Poisson's ratio & $v_{12}=v_{13}=0.28, v_{23}=0.34$ \\
Shear modulus $(\mathrm{MPa})$ & $G_{12}=G_{13}=4420, G_{23}=5000$ \\
\hline
\end{tabular}


Table 3: Mechanical properties of adhesive

\begin{tabular}{ll}
\hline Properties & Values \\
\hline Density $\left(\mathrm{kg} / \mathrm{m}^{3}\right)$ & 1960 \\
Young's modulus $(\mathrm{MPa})$ & $E=3100$ \\
Poisson's ratio & $v=0.3$ \\
\hline
\end{tabular}

\subsection{Hygrothermal aging}

Hygrothermal aging experiments were conducted to examine the moisture absorption behaviour and to determine the weight gained by specimens as a function of the time. The experiments samples were $13 \mathrm{~mm} \times 13 \mathrm{~mm} \times 9 \mathrm{~mm}$ in dimension, Figure1. Sample preparation for the SHPB technique was a difficult and critical process because it was important to ensure that both faces of the specimen were completely flat and aligned with a high degree of precision. The weight of each specimen was measured after every $96 \mathrm{~h}$ (regular period) on an analytical Precisa XT220A balance with a precision of $0.0001 \mathrm{~g}$.
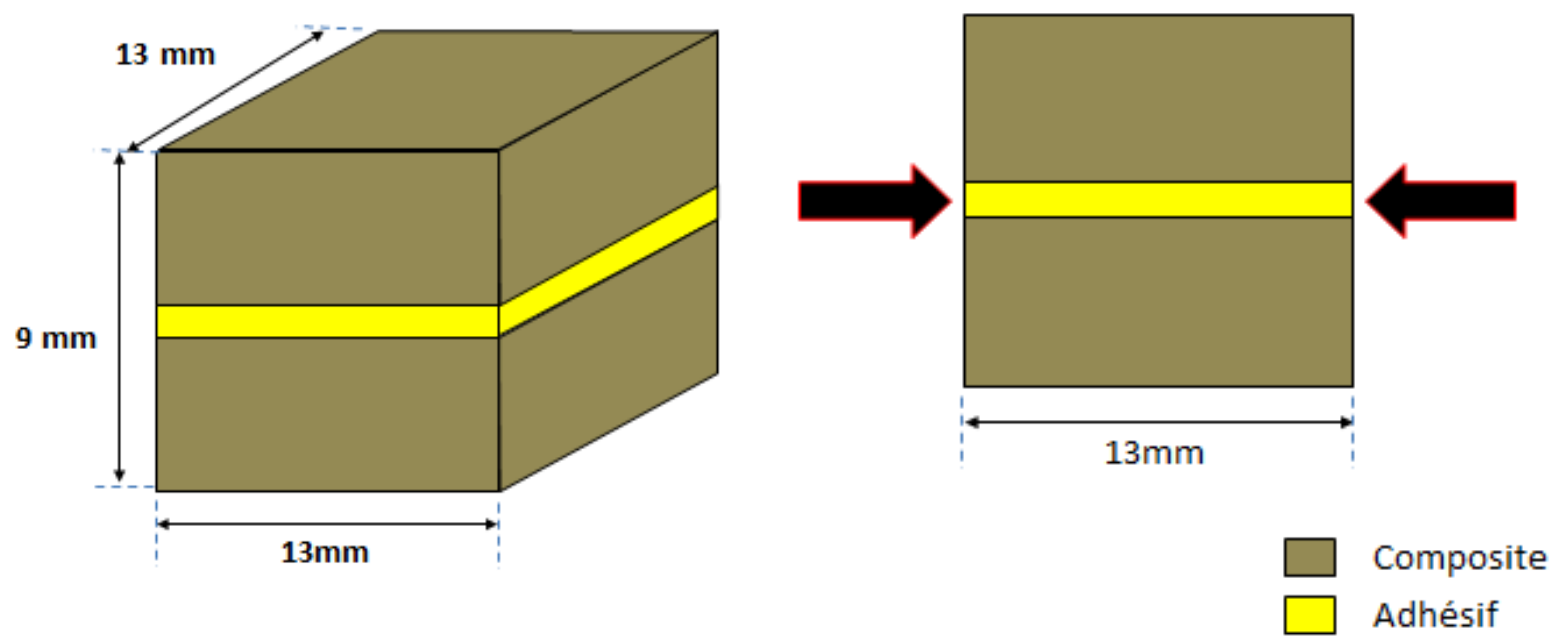

Figure 1: Adhesively bonded composite joint sample.

Adhesively bonded composite samples were subjected to following hygrothermal aging conditions: $50^{\circ} \mathrm{C}$ temperature with $80 \%$ relative humidity for various time intervals. Specimens were arranged adjacent to each other in the ASCOTT corrosion enclosure for two months, Figure 2 (a). The program utilized in this test is illustrated in Figure 2 (b). 


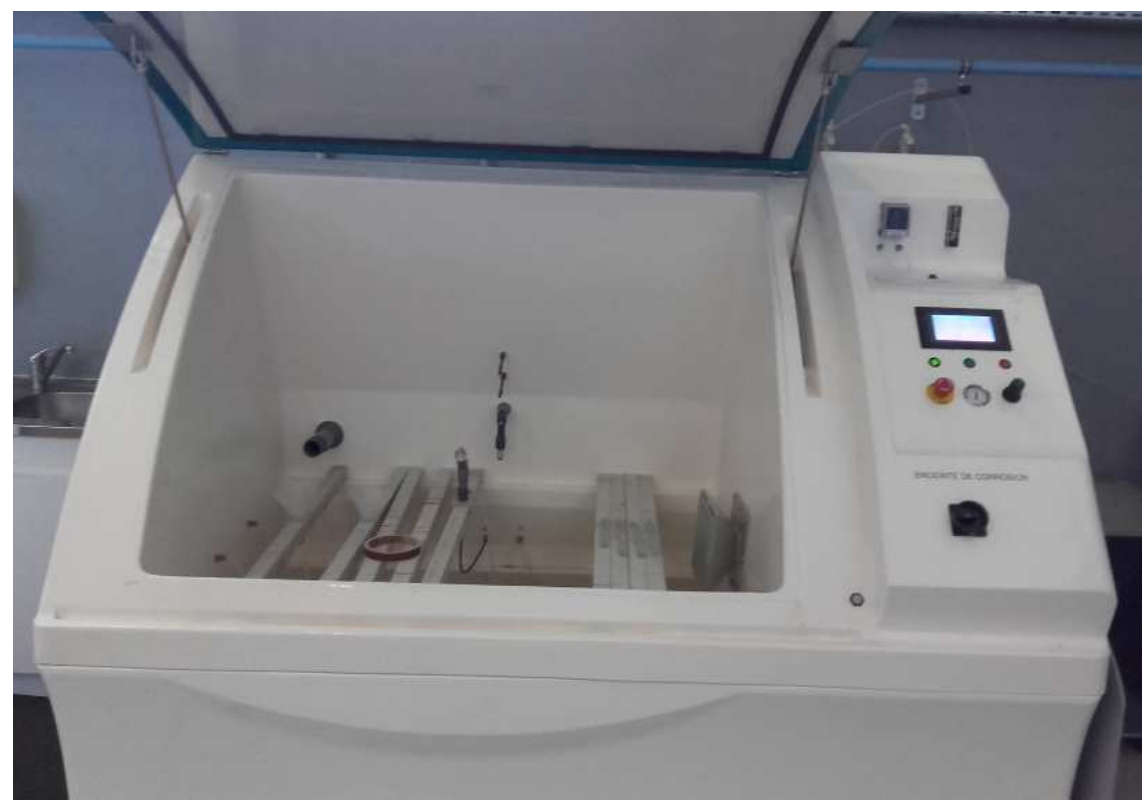

(a) ASCOTT corrosion enclosure.

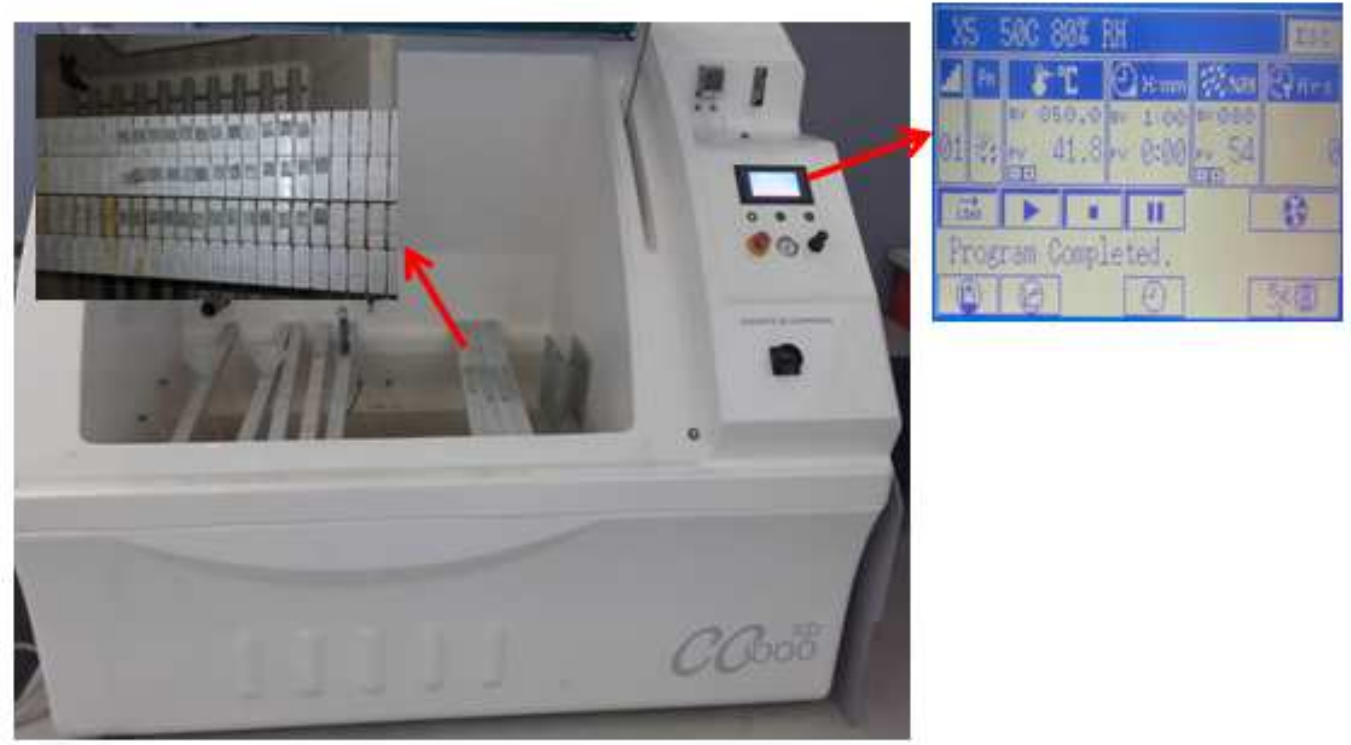

(b) Adhesively bonded composite samples and hygrothermal aging conditions

Figure 2: Hygrothermal aging of adhesively bonded composite joint specimens in the ASCOTT corrosion enclosure.

\subsection{Gravimetric analysis}

The weight of the samples was measured for each interval using Precisa XT220A balance having an accuracy of $10^{-4} \mathrm{~g}$ as discussed before. The moisture uptake content $(\mathrm{M})$ absorbed by each specimen was measured according to its weight before exposure $\left(w_{i}\right)$ and after exposure $\left(w_{f}\right)$ as follows $[27,28]$ :

$M=\frac{w_{f}-w_{i}}{w_{i}} \times 100$

The coefficient of diffusion was obtained using Eq. (2) as per the Fick's law : 
$D=\frac{\pi}{16}\left(\frac{M_{t} / M_{\tau}}{\sqrt{t} / 2 l}\right)^{2}$

Where, $M_{\tau}$ represents the maximum water uptake, $M_{t}$ is the water uptake at time $t, 2 l$ is the thickness of specimens, and D represents the diffusion coefficient.

\subsection{Dynamic compression test}

Several techniques had been used to measure the mechanical properties of composites at high strain rates but the most common one is the SHPB specifically for strain rates ranging between 500 and $10^{4} \mathrm{~s}^{-1}$ [29, 30 and 31]. A schematic and photographic representation showed that the SHPB machine, used in this study, consisted of striker bar, input bar and output bar, Figure 3-4. 2 strain gauges were placed on the incident and transmitted bar to record the experiment signals. The in-plane dynamic compressive loading was applied on a cubic specimen with $13 \mathrm{~mm} \times 13 \mathrm{~mm} \times 9 \mathrm{~mm}$ of size. The Specimens were sandwiched between two bars i.e. incident/input and transmitted/output bars. Each bar had a diameter of $20 \mathrm{~mm}$ and the length of striker, input and output bars were $0.8 \mathrm{~m}, 3 \mathrm{~m}$ and $2 \mathrm{~m}$, respectively. These bars could slide freely on the base and were properly aligned. During an impact test, the input bar was impacted by the striker bar at a specific speed which generated the stress pulse/signal. This pulse was then partially traversed to the sample and the output bar, and the rest of the signal was reflected back to the input bar. The striker velocity was adjusted by changing the pressure to achieve a range of incident load magnitudes representing compression at different strain rates.

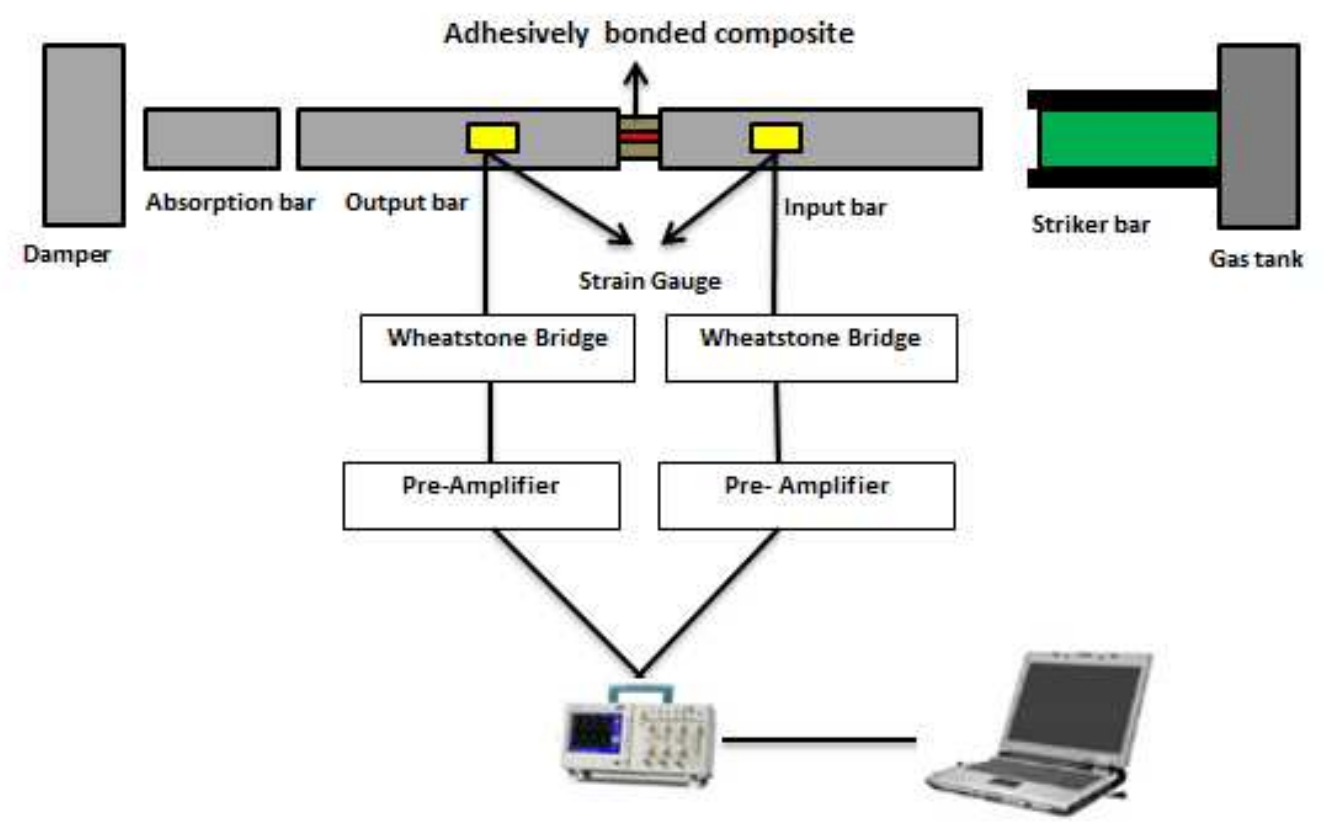

Figure 3: Schematics representation of a SHPB machine 


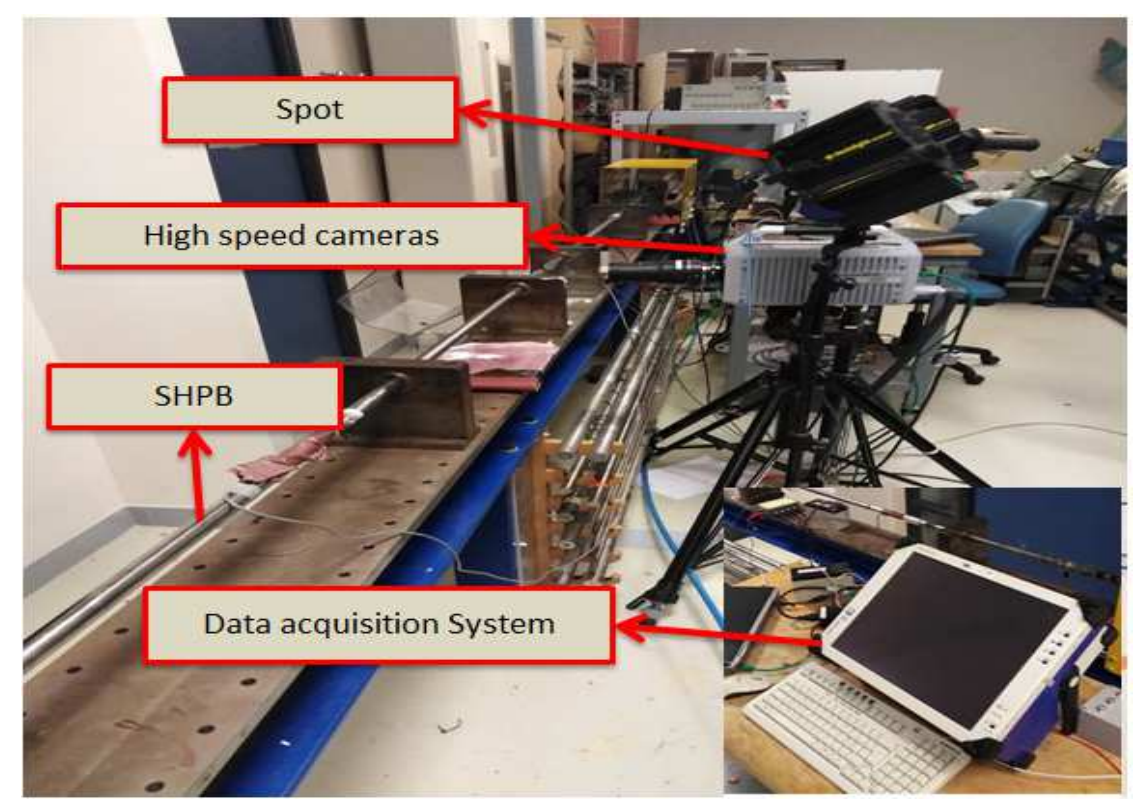

Figure 4: Photographs of the SHPB with data acquisition and High speed cameras

A typical curve, for example, of undamaged $(\mathrm{P}=1$ bar) and damaged $(\mathrm{P}=3$ bar) specimen obtained by SHPB apparatus showed the incident, transmitted and reflected signals obtained from the strain gage fixed on the bar, Figure 5. It was observed that the velocity of striker bar has a significant effect on the incident, transmitted and reflected waves. Tarfaoui et al. [32, 33 and 34] discussed in their numerous studies that the presence of second peak in the reflected wave represented the existence of macroscopic damage in the composite when they were subjected to in-plane impact and was more commonly observed for high strain rate of 3 bars, Figure 5b. So, the elastic response for the impact test at 1 bar corresponded to the undamaged case, Figure 5a.

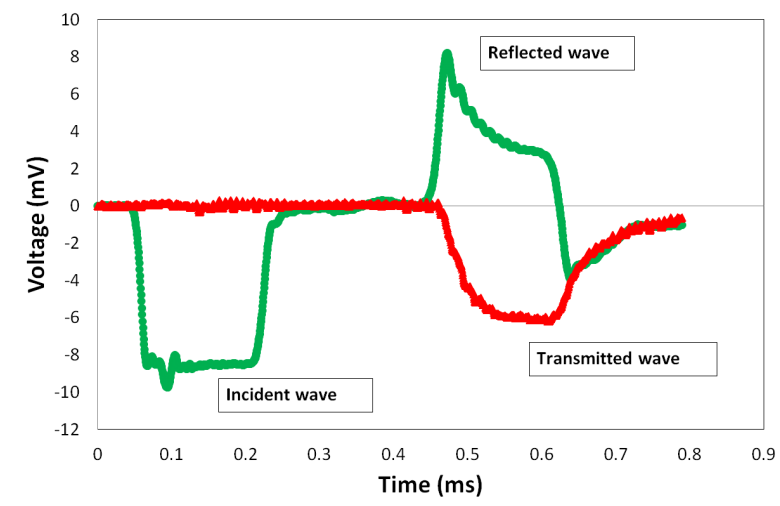

(a) $P=1$ bar

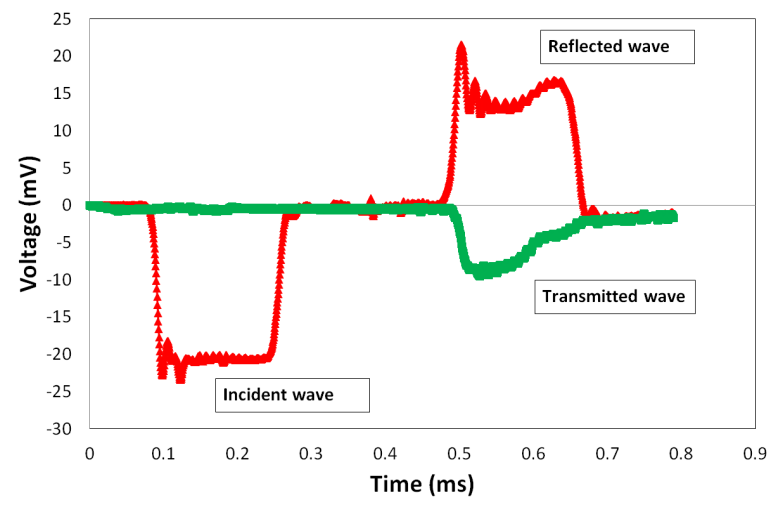

(b) $P=3$ bar

Figure 5: A typical wave obtained from the gauges placed in the incident and transmitted bars.

\section{Results and discussion}

\subsection{Moisture Absorption}

Various diffusion models could be used to understand the behaviour of homogeneous and heterogeneous material and one of the most famous and commonly used model is Fickian's one-dimensional isotropic model however, divergence from this model was often observed in 
in the literature [35], Figure 6. Langmuir-type models successfully depicted the absorption water of epoxy/fibre material [36]. When composite materials absorbed water, the local water concentration varied until equilibrium was reached. Therefore, residual stresses were caused by this inhomogeneous local swelling due to non-uniform water absorption in the material. Furthermore, the residual stresses resulted from the incompatibility between the matrix and fiber in composite laminates even with a uniform distribution of water. Thus, the induced residual stresses could lead to the creation of microcracks, especially under transient conditions, and caused further decrease of the strength of the composite.

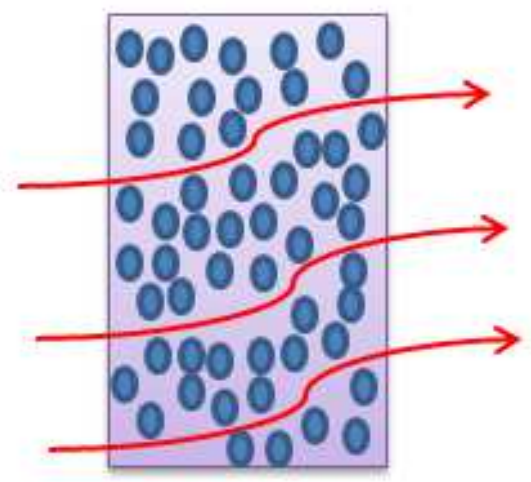

(a)

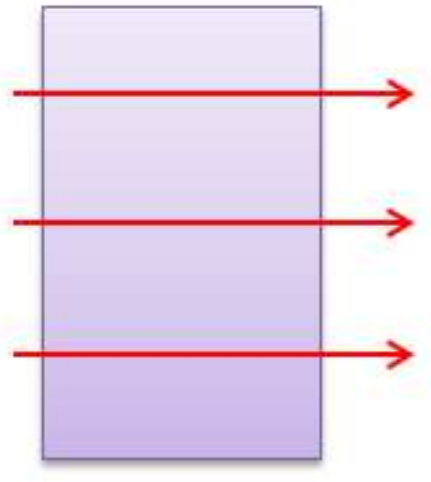

(b)

Figure 6. Comparative schematic the diffusion phenomena of homogeneous material and heterogeneous material.

During the moisture absorption at the interface, water molecules settled down in the macro voids formed by cavities and cracks, which induced further cavities and cracks, thus the interphase was gradually damaged. Humid aging was recognized as one of the main causes of long-term failure of organic matrix composite. There were several modes of humid aging such as plasticization of matrix, differential swelling, embrittlement of macromolecular skeleton by hydrolysis, osmotic cracking, hygrothermal shock and localized damage at the fiber/matrix interface [37].

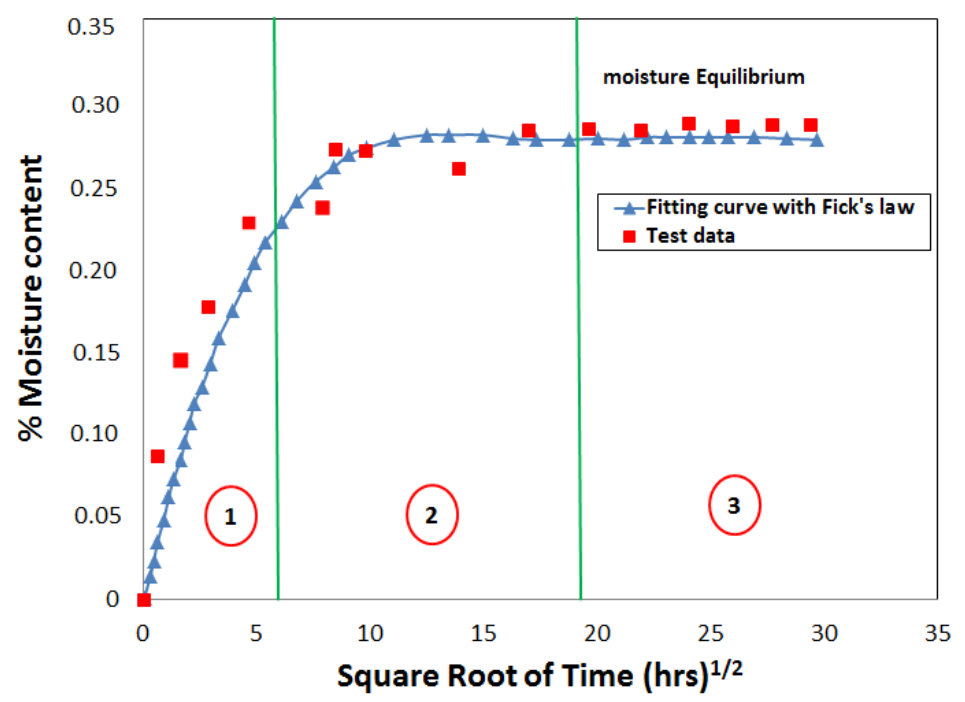

Figure 7. Moisture absorption law of adhesively bonded composite joint 


\subsection{Physical and Chemical Interactions}

The experimental data presented the average value of 10 tested samples and fitted curve was plotted by using the Fick law, Figure 7. The moisture absorption content process of adhesively bonded assemblies could be split into three periods. In the first period, the water absorption rate in the adhesively bonded composite joints was linear as a function of aging time and the moisture content rate increased rapidly with time achieving the value of 0.239 wt. $\%$ in $49 \mathrm{~h}$. The moisture content in this period was primarily caused by the presence of imperfections in composite material such as matrix micro-cracks and voids. In the second period, the moisture absorption evidently decelerated to reach the saturation point with 0.2875 $\mathrm{wt} \%$ in $400 \mathrm{~h}$ and resulted in the resin-fibre interface debonding and resin hydrolysis. In the third period, the moisture absorption curve showed that the composite moisture diffusion reached equilibrium after about $420 \mathrm{~h}$ of aging time.

The study of the degradation mechanism of composite materials should take into account chemical as well as physical aspects of ageing. Composite materials undergoes a slow degradation process when subjected to physical and chemical ageing due to water molecule sorption. Sorbed moisture acts as both a plasticizer and hydrolysis promoting agent, decreasing the mechanical integrity of the ester matrix to a degree which is dependent upon the temperature to which the material has been previously exposed. However, while plasticization is a reversible phenomenon which disappears upon drying, chemical degradation is irreversible. The chemical interactions that occur during moisture absorption are mostly due to hydrolysis and leaching effects. In such case, water breaks down the ester chain in the following manner and diffuses into the matrix materials. Since moisture cannot penetrate fibers, the behavior of diffusing moisture in composites is usually affected by the resin properties. Apicella and his colleagues [38] proposed that there are three modes of sorption:

- Bulk dissolution of water in the polymer network;

- Moisture absorption onto the surface of vacuoles which define the excess free volume of the glassy structure

- Hydrogen bonding between polymer hydrophilic groups and water. If the first two modes occur consecutively, a dual sorption behavior can be detected.

In our case, the effects of moisture result both physical and chemical changes in bonded glass/vinylester composites. The physical mechanism for moisture absorption is generally observed to be a mass diffusion process followed by Fick's law of diffusion. When a vinylester resin absorbs water, the local degree of swelling depends on the local water concentration. As a result, the more swollen regions experience a compressive force, whereas less swollen regions experience tensile forces. We have followed the evolution of the dimensions of three specimens during the ageing process (Table 4) why the swelling describes volumetric changes due to moisture content alone, independent of thermal expansion. Gazit [39] showed that the weight increase of moisture was proportional to the linear dimensional change, and was the same for all samples having the same reinforcements at all levels of ambient humidity. 
Table 4: Variation the dimension of the samples

\begin{tabular}{|c|c|c|c|c|c|}
\hline Sample & Time (h) & $\mathbf{H}(\mathrm{mm})$ & $\mathbf{L}(\mathbf{m m})$ & I (mm) & $\begin{array}{c}\text { Volume } \\
\left(\mathrm{mm}^{3}\right)\end{array}$ \\
\hline \multirow{6}{*}{1} & 0 & 9.7 & 12.84 & 12.63 & 1573.04124 \\
\hline & 216 & 9.66 & 12.89 & 12.64 & 1573.89994 \\
\hline & 648 & 9.75 & 12.87 & 12.63 & 1584.84398 \\
\hline & 864 & 9.7 & 12.89 & 12.67 & 1584.16811 \\
\hline & Average & 9.7025 & 12.8725 & 12.6425 & 1578.9883 \\
\hline & St.Dev. & 0.03685557 & 0.02362908 & 0.018929694 & 6.38692237 \\
\hline \multirow{6}{*}{2} & 0 & 9.28 & 12.99 & 13.04 & 1571.93549 \\
\hline & 216 & 9.28 & 13 & 12.96 & 1563.4944 \\
\hline & 648 & 9.19 & 12.96 & 13.04 & 1553.0953 \\
\hline & 864 & 9.22 & 12.98 & 13.04 & 1560.56982 \\
\hline & Average & 9.2425 & 12.9825 & 13.02 & 1562.27375 \\
\hline & St.Dev. & 0.045 & 0.01707825 & 0.04 & 7.78859314 \\
\hline \multirow{6}{*}{3} & 0 & 9.36 & 12.94 & 13.22 & 1601.18525 \\
\hline & 216 & 9.35 & 12.93 & 13.14 & 1588.56687 \\
\hline & 648 & 9.37 & 12.94 & 13.22 & 1602.89592 \\
\hline & 864 & 9.39 & 12.97 & 13.14 & 1600.29826 \\
\hline & Average & 9.3675 & 12.945 & 13.18 & 1598.23657 \\
\hline & St.Dev. & 0.01707825 & 0.01732051 & 0.046188022 & 6.53599977 \\
\hline
\end{tabular}

Since water is polar, it is capable of forming hydrogen bonds with hydroxyl groups. Therefore, interchain hydrogen bonds can be disrupted to increase the intersegmental hydrogen bond length. These mechanisms basically reduces the Tg of the wet sample and are known as plasticization and swelling of polymer matrix. These phenomena are coupled and in some cases are the origin of microstructural damage like fiber debonding and matrix cracking [40]. On the other hand, in the resin-rich region of matrix, the swelling of the matrix is significant. This phenomenon leads to an interfacial decohesion between resin and fibres.

In other works, Lee [41] shows that the water absorption causes resin plasticization concurrently with swelling and lowering of its glass transition temperature. These effects usually accompany modulus changes of the composite material (such as shifting of the relaxation modulus to shorter times). Modulus changes due to water can be accelerated with increasing temperature.

\section{Effects of moisture absorption on the dynamic behaviour}

\section{a. Mechanical behaviour}

In order to ensure the reproducibility of dynamic tests, each test, for adhesively bonded composite joint specimen, was repeated three times, Figure 8 . The strain rate vs time and the Stress-Strain variation were plotted to analyse the mechanical response of the tested specimens under different impact pressures. 

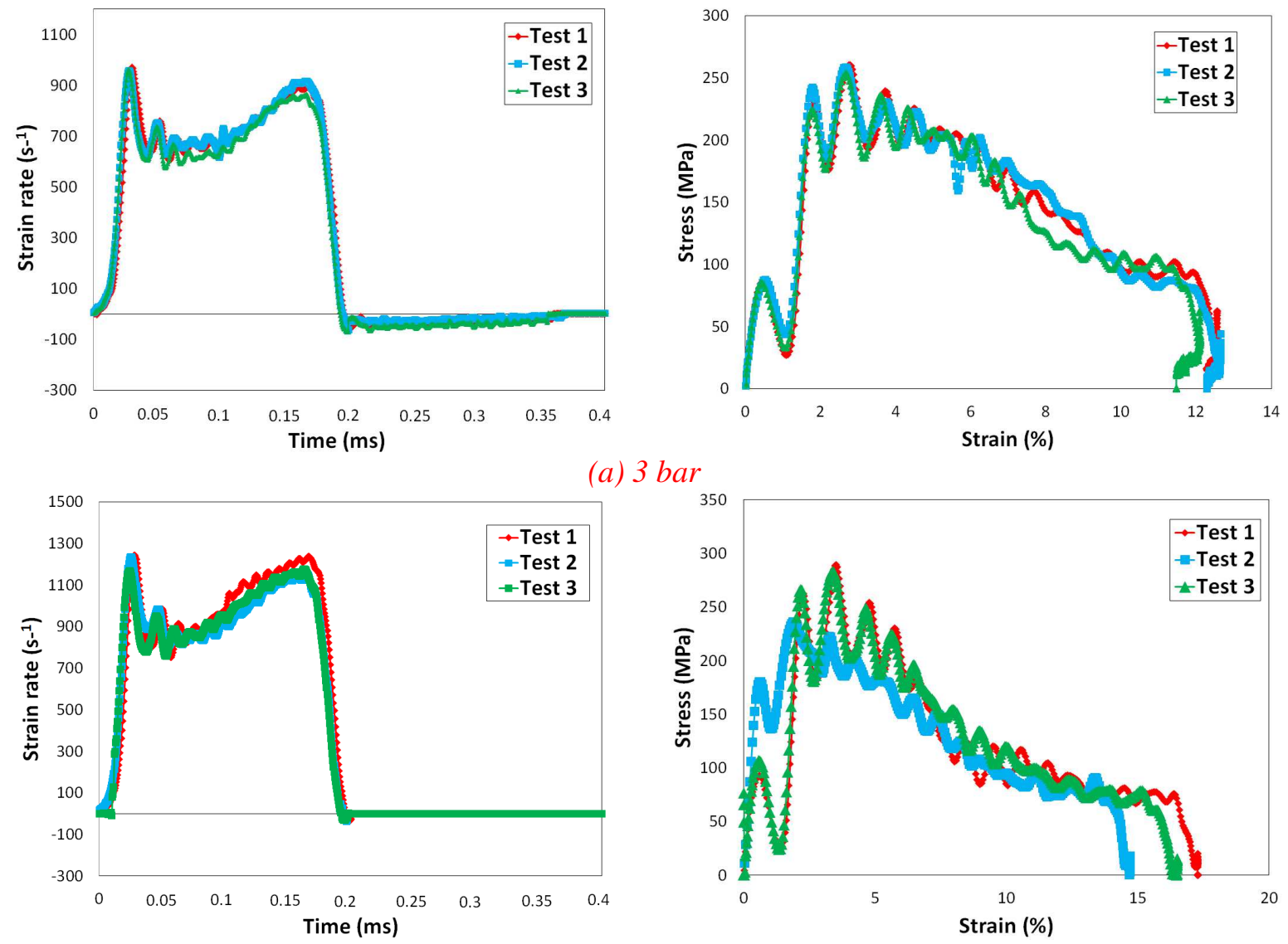

(b) 4 bar

Figure 8. Test reproducibility for different impact pressure, $\mathrm{t}=648 \mathrm{~h}$.

The moisture and the temperature could define the elastic and thermoplastic properties of a material. However, an augmentation in moisture and temperature, which could naturally increase the molecular motion of the material, quickly changed the form and the volume of the composites. Such distortion was made more complicated when the material was subjected to dynamic compression loading conditions. The effect of aging time $0 \mathrm{~h}$ to 864 on stressstrain response of adhesively bonded composite joints subjected in-plan dynamic compression for 1, 2, 3, 4 bars respectively, is presented in Figures 9.

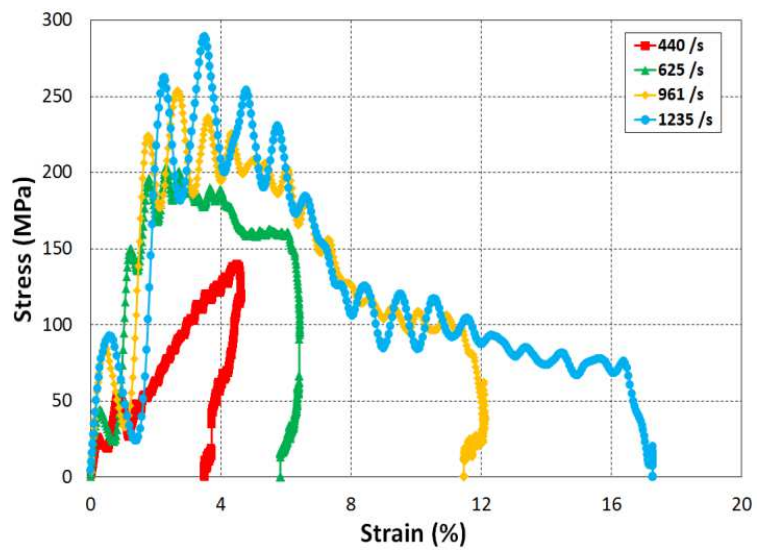

(a) $t=0 h$

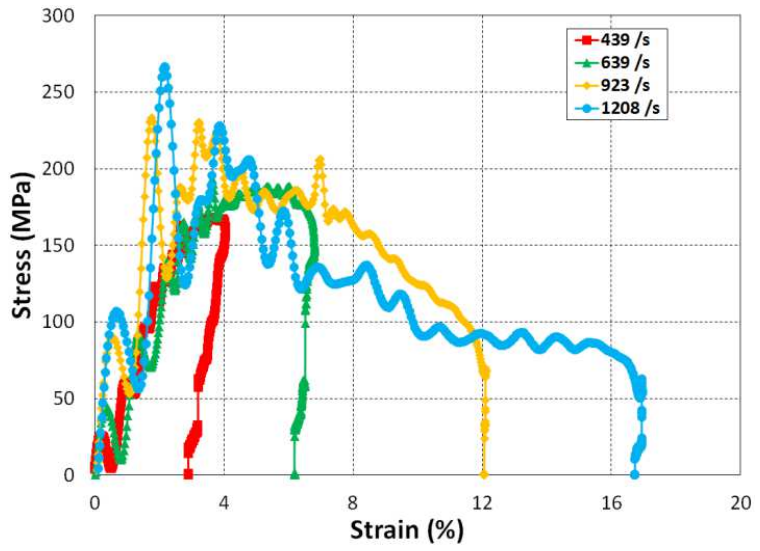

(b) $t=216 \mathrm{~h}$ 


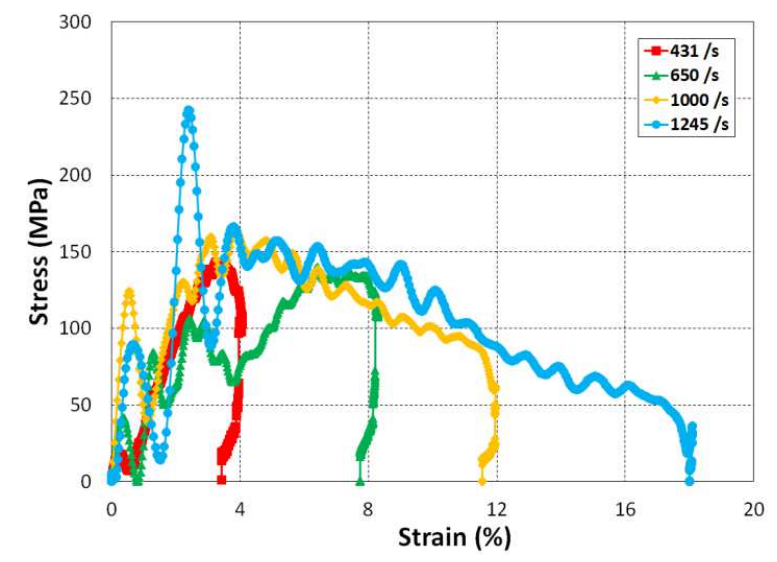

(c) $t=648 \mathrm{~h}$

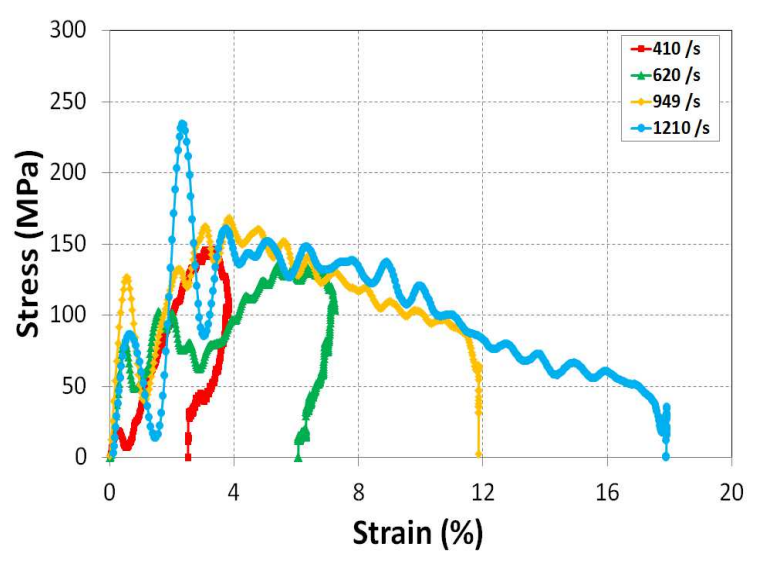

(d) $t=864 h$

Figure 9. Stress-strain curves of the specimen for different aging time under in-plan

loading

It was observed that the dynamic compressive behaviour of the composite assemblies was highly influenced by the strain rate and the aging time. It was also observed that the influence of the moisture on the experimental stress-strain curves was comparatively more prominent at the lower strain rate than at the higher strain rate. This clearly showed that the matrix dominant properties were more prone to the strain rate rather than the fibre dominant properties for both dry and humid samples. The maximum stress corresponded as the ultimate stress and the appearance of damage in the samples after which the samples lost their loadbearing capacity. It was also observed that the stress-strain trend was similar over the linear elastic response for all impact tests, with recoverable deformation and without any damage. On the other hand, it was seen that in the case of undamaged tests, the samples return to the initial state with almost negligible plastic deformation while in the case of the damaged specimens, the appearance of the first peak in the elastic response showed the initiation of microscopic damage modes such as matrix cracking. The in-plane matrix cracking further encouraged micro-buckling, the fibres kinking, fibre splitting, and fibre crushing which resulted in debonding, delamination and the final failure. The appearance of the second peak in the strain rate curves further confirmed the presence of macro damage [42]. It could be concluded that the initial region of the non-linearity in the stress-strain curves was principally because of the viscoelastic nature of the Polyester polymer, whereas the non-linearity before the final failure was due to matrix cracking, and decrease in the elastic modulus. This reduction of properties was because of the aging time and increase of the moisture content in the composite. Results of the study also indicated plasticizing of matrix which was reflected through increased ductility of the samples and reduced slope of the stress-strain curves.
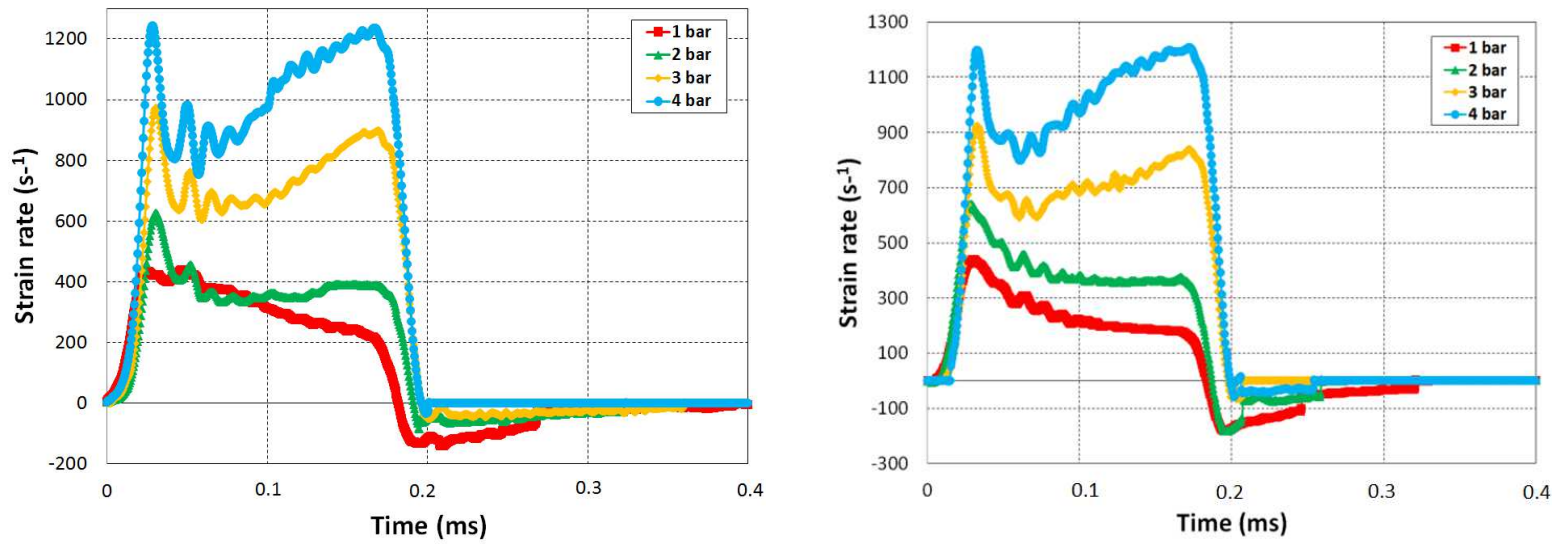
(a) $t=0 h$

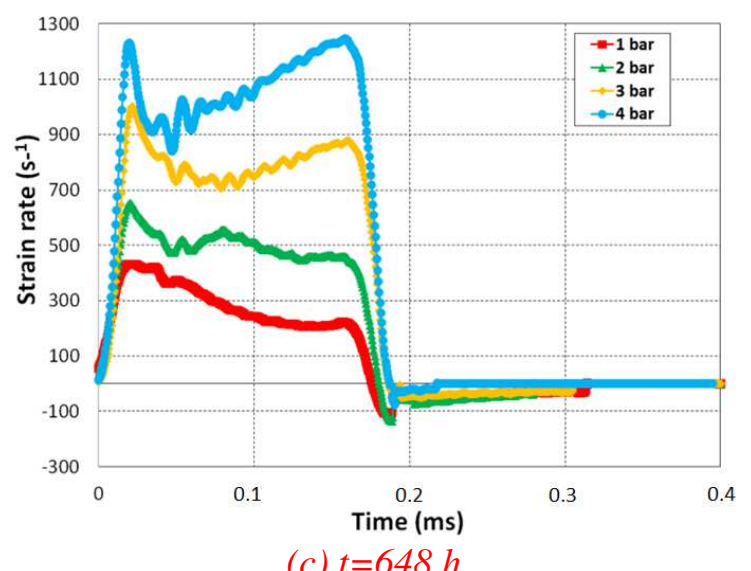

(b) $t=216 \mathrm{~h}$

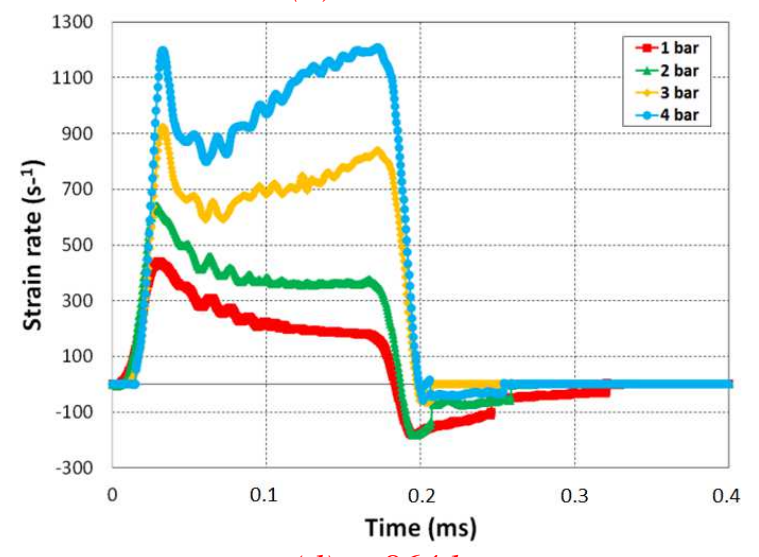

(d) $t=864 \mathrm{~h}$

Figure 10: The strain rate-time curves of the specimen for different aging time under in-plan loading

The variation of the strain rate vs. time was plotted for aging time $0 \mathrm{~h}$ to 864 at different impact pressures for all the bonded composite joint specimens, Figure 10. The damage became visible only for the higher impact pressures which was justified with the presence of a second peak in the signal and became more evident with an increase in the impact pressures, reflecting the accumulation of failure modes in the specimen. In contrary, for low impact pressure, there was only residual "plastic" deformation because of matrix micro cracking. The tested specimens were damaged by fibre kinking at low strain rates, and showed interfacial separation and delamination for the high strain rate. Absorbed moisture caused plasticization of polymer matrix, altered stress state and degraded the fibre/matrix interface. Thus, critical understanding of moisture absorption and desorption behaviour was required for predicting long-term material and structural performance. For example, recently, an investigation was conducted to study the diffusion behaviour of 3D braided composite using finite element models [43].

\section{b. Damage modes}

Optical microscopy (OM) and Scanning Electron Microscopy (SEM) were used to visualize the different modes of damage. OM provided information about the microstructure and SEM further elaborated the comprehensive information about matrix, fibres and fibre/matrix interfaces of the adhesively bonded composite joints. It was noted that the fibre and matrix were closely bonded before hygrothermal aging. Damage initiation included the formation of a ' $V$ ' shaped shear band and appearance of delamination on its tip. As the damage mechanism progressed, it demonstrated matrix failure, fibre pull-out, and severe delamination between the plies. Micro-cracks appeared at the interface between the matrix and the fibre of the specimen aged for 216 hours, as shown in Figure 11. The interface detachment developed and progressed in the form of long cracks as the hygrothermal aging time was increased to maximum 864 hours. The obvious interfacial degradation between the adhesive and the composite of adhesively bonded composite joints was detected because of the absorbed moisture. In addition, the results indicated that the hygrothermal effect caused chemical modifications, dimensional changes (swelling) and plasticization in the resin matrix and loss of interfacial strength between the adhesive/composite assemblies. Moreover, the fibre/matrix bond weakened with the increase of the moisture content. All of these factors affected the impact strength of the composite. 
Aging time
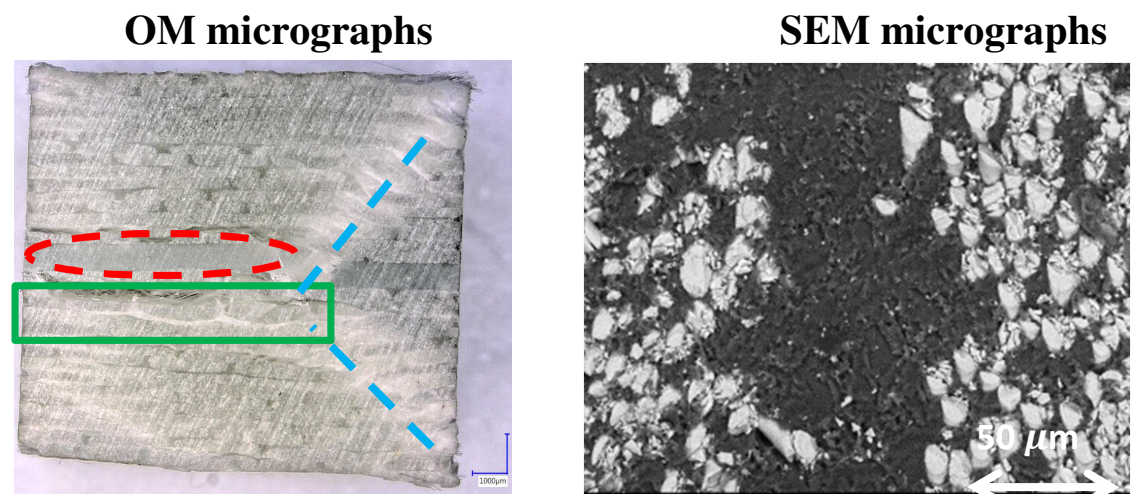

$216 \mathrm{~h}$

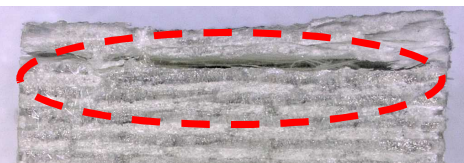

$648 \mathrm{~h}$
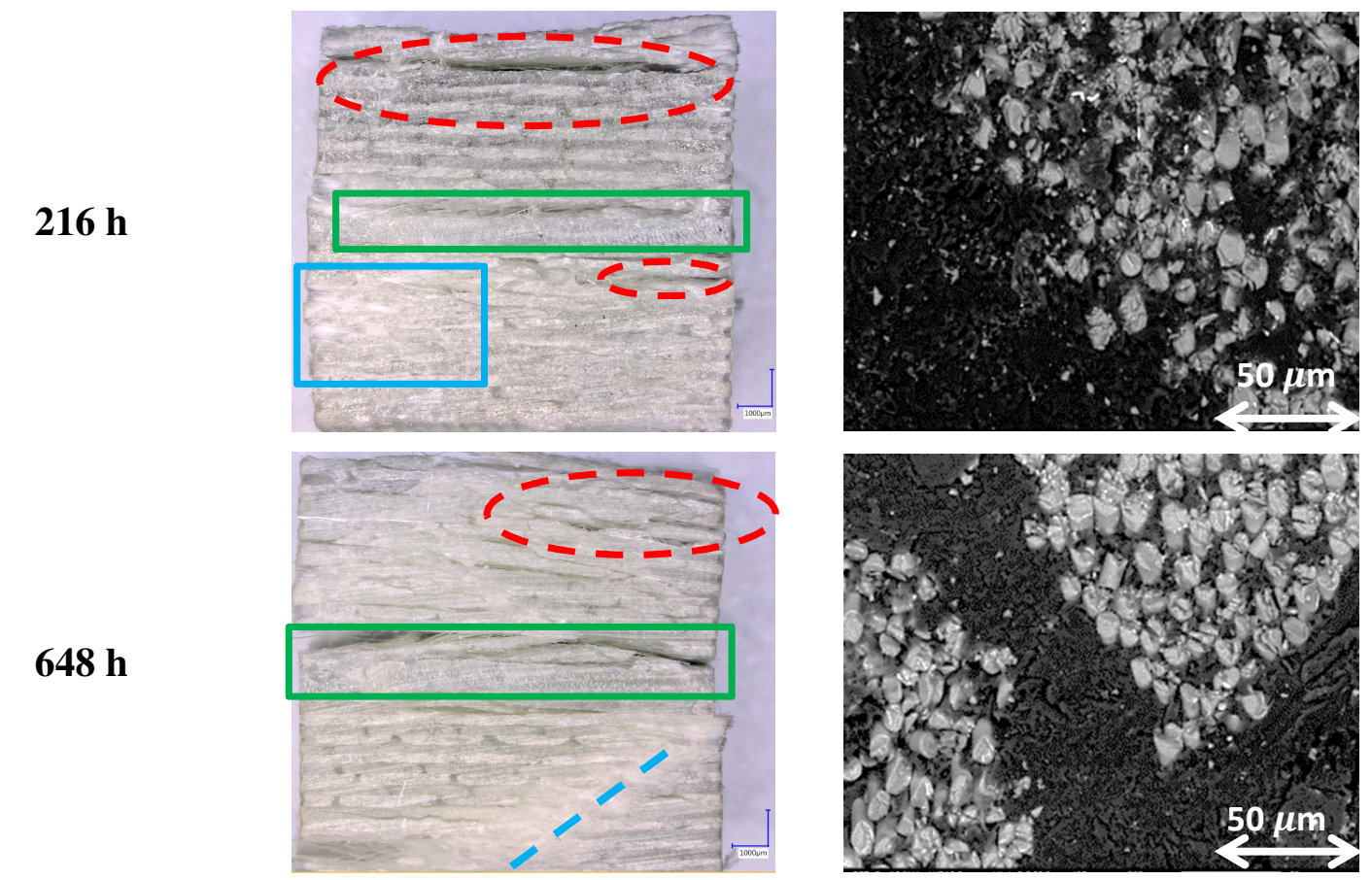

864 h
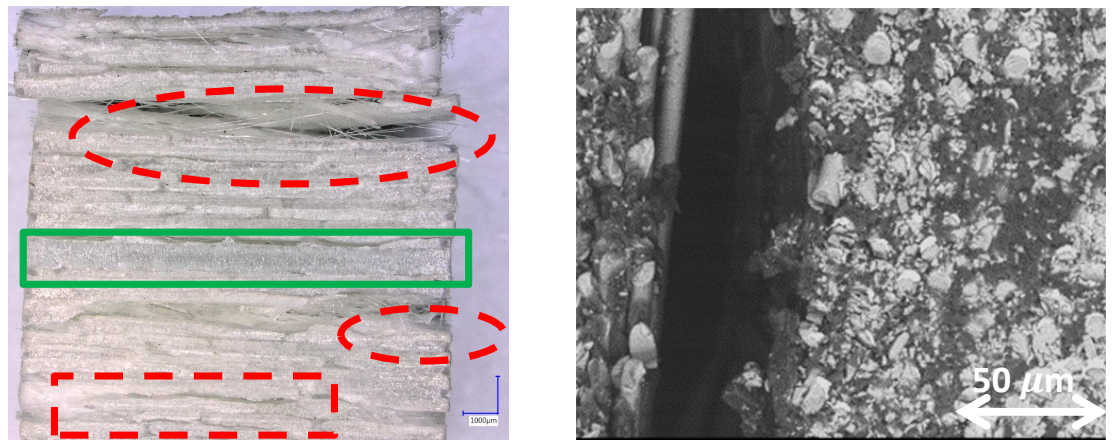

- Cohesive failure: delamination

- Adhesive failure

- $\quad$ Adherent-adhesive (Interface failure)

$>$ Formation damage zone (Shape V)

- Shearing through the layers-Macrocracks

- Transverse cracking in the layers

- Cracks in the external layers

- Internal shear cracking

- Interlaminar cracking

Figure 11: OM and SEM micrographs of adhesive bonded composite subjected to dynamic compression test, $\mathrm{P}=3$ bar. 
Figure 12 presents the effect of absorbed moisture content on the fracture strength at each impact pressure. In all the cases, the maximum strength was increased as a function of the impact pressure for all ageing times. The increase in strength and modulus indicated that the material was becoming relatively brittle and stiffer [40]. However, the results also showed that the fracture strength was decreasing by increasing the aging time for each impact pressure which was explained by the fact that temperature and humidity significantly altered the composite and weakened it. The plasticization of the matrix was the principal factor to explain this decrease of properties at high strain rate. Therefore, the behaviour of matrix played a more significant role and was more strain rate responsive than fibre in the determination of the high strain rate material response of polymer matrix composites.

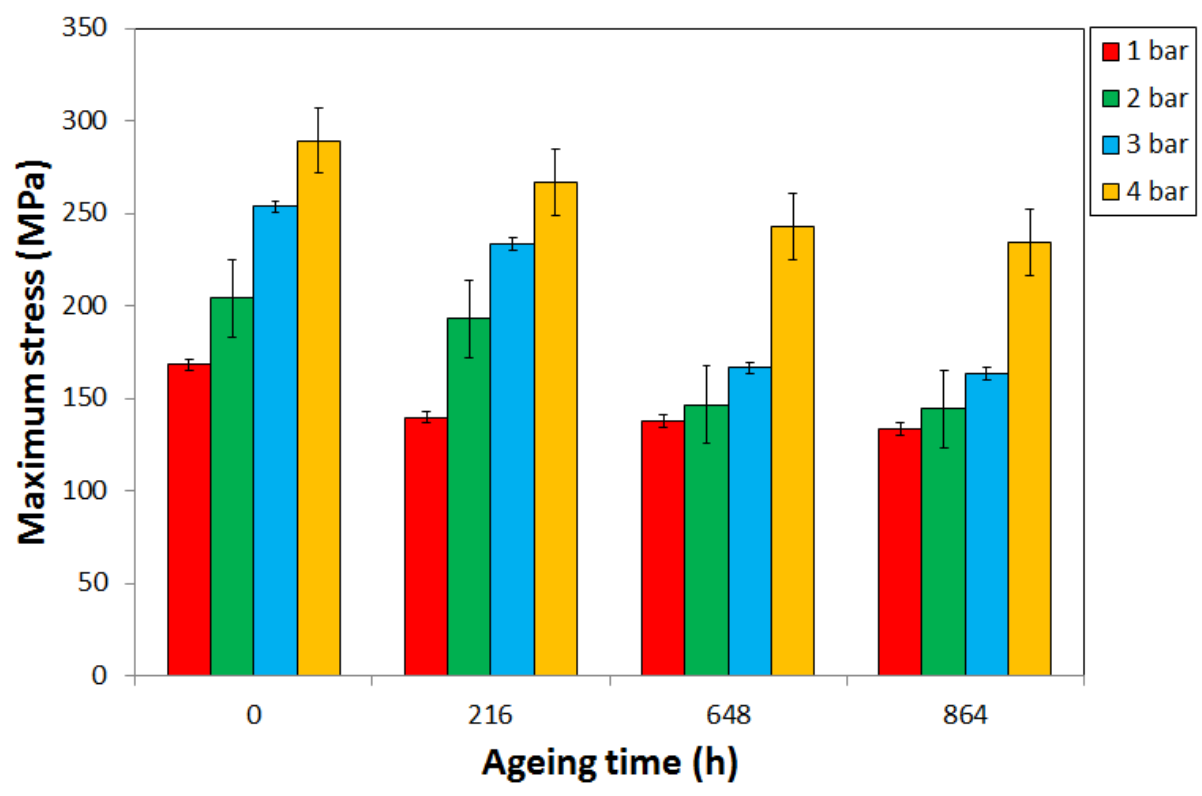

Figure 12: Maximum stress vs the ageing time.

\section{Conclusion}

In this article, adhesively bonded composite joints were aged at $50^{\circ} \mathrm{C}$ temperature with $80 \%$ of the relative humidity for various periods of time intervals i.e. $0 \mathrm{~h}, 216 \mathrm{~h}, 648 \mathrm{~h}$ and $864 \mathrm{~h}$. The stress-strain responses were determined for high strain rates ranging from 445 to $1240 \mathrm{~s}^{-1}$. The failure modes were observed by OM and SEM for each specimen. The amount of moisture absorption for adhesively bonded composite joints was observed to be $0.28 \%$ by weight at the saturation level. In all the cases, failure stress, failure strain and initial modulus were seemed to be decreasing by increasing the moisture absorption and increasing with higher strain rates. Moreover, the reduction of fracture strength because of the moisture absorption was more at higher strain rates, when the sample was loaded in the in-plane direction. This was due to the fact that the matrix properties played more significant role and were more affected than the fiber properties. It had been concluded that materials showed a strength dependency on strain rate and there was considerable increase in dynamic parameters with the increase in the strain rate. As the strain rate was increased, more damage modes were visible i.e. matrix cracks, delamination and failure of adhesive interlayer. Specimens failed due to laminate splitting at low strain rates while delamination and adhesive/adherent interfacial separation dominated at the high strain rates. Moreover, the swelling and plasticization, hydrolysis and leaching effects were the main physical and chemical 
degradations of polymer structures because of the water absorption which were reflected through increased ductility and reduced stiffness of the samples.

The effect of moisture or water on the properties of polymer composites is an important issue and that is why further study is necessary. In this context, a future study is recommended to examine the effects of moisture and temperature on high strain rate behaviour for different structures such as hybrid joint, different composite, adhesive and matrix materials.

\section{Reference}

[1] Nachtane, M., Tarfaoui, M., Saifaoui, D., El Moumen, A., Hassoon, O. H., \& Benyahia, H. (2018). Evaluation of durability of composite materials applied to renewable marine energy: Case of ducted tidal turbine. Energy Reports, 4, 31-40.

[2] Mangalgiri, P. D. (1999). Composite materials for aerospace applications. Bulletin of Materials Science, 22(3), 657-664.

[3] Shahawy, M. A., Beitelman, T., Arockiasamy, M., \& Sowrirajan, R. (1996). Experimental investigation on structural repair and strengthening of damaged prestressed concrete slabs utilizing externally bonded carbon laminates. Composites Part B: Engineering, 27(3-4), 217-224.

[4] Sassi, S., Tarfaoui, M., \& Yahia, H. B. (2018). In-situ heat dissipation monitoring in adhesively bonded composite joints under dynamic compression loading using SHPB. Composites Part B: Engineering, 154, 64-76.

[5] Sassi, S., Tarfaoui, M., \& Yahia, H. B. (2018). Thermomechanical behavior of adhesively bonded joints under out-of-plane dynamic compression loading at high strain rate. Journal of Composite Materials, 0021998318777048.

[6] Wu, L., Hoa, S. V., \& Ton-That, M. T. (2004). Effects of water on the curing and properties of epoxy adhesive used for bonding FRP composite sheet to concrete. Journal of applied polymer science, 92(4), 2261-2268.

[7] Gargano, A., Pingkarawat, K., Pickerd, V., Delaney, T., Das, R., \& Mouritz, A. P. (2018). Effect of seawater immersion on the explosive blast response of a carbon fibre-polymer laminate. Composites Part A: Applied Science and Manufacturing, 109, 382-391

[8] Ray, B.C. (2004). Thermal Shock on Interfacial Adhesion of Thermally Conditioned Glass Fiber/epoxy Composites, Materials Letters, 58:2175-2177. 20.

[9] Ray, B.C. (2004). Effects of Crosshead Velocity and Sub-zero Temperature on Mechanical Behavior of Hygrothermally Conditioned Glass Fiber Reinforced Epoxy Composites, Materials Science and Engineering, A379:39-44. 
[10] Dogan, A., \& Arman, Y. (2018). The Effect of Hygrothermal Aging on the Glass and Carbon Reinforced Epoxy Composites for Different Stacking Sequences. Mechanika, 24(1), 19-26.

[11] Ma, Y., Jin, S., Ueda, M., Yokozeki, T., Yang, Y., Kobayashi, F., ... \& Hamada, H. (2018). Higher performance carbon fiber reinforced thermoplastic composites from thermoplastic prepreg technique: Heat and moisture effect. Composites Part B: Engineering, 154, 90-98.

[12] Majerski, K., Surowska, B., \& Bienias, J. (2018). The comparison of effects of hygrothermal conditioning on mechanical properties of fibre metal laminates and fibre reinforced polymers. Composites Part B: Engineering, 142, 108-116.

[13] Lee, M.C. and N.A. Peppas. "Water transport in epoxy resins." Progress in Polymer Science. Vol. 18, No. 5 (1993) 947-961.

[14] Koenig, J.L. and H. Emadipour. "Mechanical Characterization of the Interfacial Strength of Glass-Reinforced Composites." Polymer Composites. Vol. 6, No. 3 (1985) 142-150.

[15] Schutte, C.L. "Environmental durability of glass-fiber composites." Materials Science and Engineering. Vol. R13 (1994) 265-324.

[16] Mijovic, J. and H. Zhang. "Molecular Dynamics Simulation Study of Motions and Interactions of Water in a Polymer Network." Journal of Physical Chemistry B. Vol. 180, No. 8 (2004) 2557-2563.

[17] Megel, M., L. Kumosa, T. Ely, D. Armentrout, and M. Kumosa. "Initiation of stresscorrosion cracking in unidirectional glass/polymer composite materials." Composite Science and Technology. Vol. 61 (2001) 231-246.

[18] Jiang, X., Kolstein, H., Bijlaard, F., \& Qiang, X. (2014). Effects of hygrothermal aging on glass-fibre reinforced polymer laminates and adhesive of FRP composite bridge: Moisture diffusion characteristics. Composites Part A: Applied Science and Manufacturing, 57, 49-58.

[19] Pillay, S., Vaidya, U. K., \& Janowski, G. M. (2009). Effects of moisture and UV exposure on liquid molded carbon fabric reinforced nylon 6 composite laminates. Composites Science and Technology, 69(6), 839-846.

[20] Hosur, M. V., Islam, S. W., Vaidya, U. K., Dutta, P. K., \& Jeelani, S. (2003). Effects of temperature and moisture on the high strain rate compression response of graphite/epoxy composites. Journal of engineering materials and technology, 125(4), 394-401.

[21] Sousa, J. M., Correia, J. R., Firmo, J. P., Cabral-Fonseca, S., \& Gonilha, J. (2018). Effects of thermal cycles on adhesively bonded joints between pultruded GFRP adherends. Composite Structures. 
[22] Benyahia, H., Tarfaoui, M., El Moumen, A., Ouinas, D., \& Hassoon, O. H. (2018). Mechanical properties of offshoring polymer composite pipes at various temperatures. Composites Part B: Engineering, 152, 231-240.

[23] Jojibabu, P., Ram, G. J., Deshpande, A. P., \& Bakshi, S. R. (2017). Effect of carbon nano-filler addition on the degradation of epoxy adhesive joints subjected to hygrothermal aging. Polymer Degradation and Stability, 140, 84-94.

[24] Akderya, T., Kemiklioğlu, U., \& Sayman, O. (2016). Effects of thermal ageing and impact loading on tensile properties of adhesively bonded fibre/epoxy composite joints. Composites Part B: Engineering, 95, 117-122.

[25] Rafiq, A., \& Merah, N. (2019). Nanoclay enhancement of flexural properties and water uptake resistance of glass fiber-reinforced epoxy composites at different temperatures. Journal of Composite Materials, 53(2), 143-154.

[26] Sassi, S., Tarfaoui, M., \& Yahia, H. B. (2018). An investigation of in-plane dynamic behavior of adhesively-bonded composite joints under dynamic compression at high strain rate. Composite Structures, 191, 168-179.

[27] Firdosh, S., Murthy, H. N., Angadi, G., \& Raghavendra, N. (2018). Investigation of water absorption characteristics of nano-gelcoat for marine application. Progress in Organic Coatings, 114, 173-187.

[28] Nachtane, M., Tarfaoui, M., Saifaoui, D., \& Hilmi, K. (2017, April). Hygrothermal and mechanical performance evaluation of glass-polyester composite for renewable marine energies. In 13ème congrès de mécanique (cmm2017).

[29] Pang, S., Tao, W., Liang, Y., Liu, Y., \& Huan, S. (2018). A modified method of pulse-shaper technique applied in SHPB. Composites Part B: Engineering.

[30] Zhao, H., \& Gary, G. (1996). On the use of SHPB techniques to determine the dynamic behavior of materials in the range of small strains. International Journal of Solids and structures, 33(23), 3363-3375.

[31] Khosravani, M. R., \& Weinberg, K. (2018). A review on split Hopkinson bar experiments on the dynamic characterisation of concrete. Construction and Building Materials, 190, 1264-1283.

[32] Tarfaoui, M., \& Nachtane, M. (2018). Can a three-dimensional composite really provide better mechanical performance compared to two-dimensional composite under compressive loading?. Journal of Reinforced Plastics and Composites, 0731684418802028 .

[33] Tarfaoui, M., \& Nachtane, M. (2018). Staking lay-up effect on dynamic compression behaviour of E-Glass/epoxy composite materials: Experimental and numerical investigation. 
[34] Tarfaoui, M. (2011). Experimental investigation of dynamic compression and damage kinetics of glass/epoxy laminated composites under high strain rate compression. In Advances in Composite Materials-Ecodesign and Analysis. InTech.

[35] Chateauminois A, Chabert B, Soulier JP and Vincent L. Hygrothermal ageing effects on the static fatigue of Glass/Epoxy composites. Composites. 1998;24(7):547- 555.

[36] Carter HG And Kibler KG. Langmuir-Type Model for Anomalous Moisture Diffusion In Composite Resins. J Compos Mater. April1978;12:118-31.

[37] Merdas, I., Thominette, F., Teharkhtchi, A. and Verdu, J. (2002). Factors Governing Water Absorption by Composite Matrices, Composites Science and Technology, 62:487-492.

[38] Apicella, A., Nicolais, L., Astarita, G., \& Drioli, E. (1981). Hygrothermal history dependence of equilibrium moisture sorption in epoxy resins. Polymer, 22(8), 10641067.

[39] Gazit, S. (1978). Dimensional changes in glass-filled epoxy resin as a result of absorption of atmospheric moisture. Journal of Applied Polymer Science, 22(12), 3547-3558.

[40] Haque, A., \& Hossain, M. K. (2003). Effects of Moisture and Temperature on High Strain Rate Behavior of S2-Glass-Vinyl Ester Woven Composites. Journal of composite materials, 37(7), 627-647.

[41] Lee, M. C., \& Peppas, N. A. (1993). Water transport in epoxy resins. Progress in polymer science, 18(5), 947-961.

[42] Tarfaoui, M., El Moumen, A., \& Yahia, H. B. (2018). Damage detection versus heat dissipation in E-glass/Epoxy laminated composites under dynamic compression at high strain rate. Composite Structures, 186, 50-61.

[43] Zheng, H., Zhou, C., \& Yuan, Y. (2019). Meso-scale finite element modeling of moisture diffusion in 3D braided composite. International Journal of Heat and Mass Transfer, 129, 862-872. 